\title{
DEMOGRAPHIC CHARACTERISTICS FOR SUSTAINABILITY OF GEMMEINSCHAFT-TYPE OF RURAL COMMUNITIES IN DEPOPULATION ASSOCIATED WITH AGING IN NORTHERN KYOTO AREAS, JAPAN
}

\section{Yoshio Kawamura}

Kyoto Prefectural College of Agriculture and Ryukoku University, Japan.

E-mail: yoshiokawamura@ad.ryukoku.ac.jp

Citation: Kawamura, Y. 2019. Demographic Characteristics for Sustainability of GemmeinschaftType of Rural Communities in Depopulation Associated With Aging in Northern Kyoto Areas, Japan. J. Asian Rur. Stud. 3(1): 62-69

\begin{abstract}
Like other mountainous areas in Japan, the northern areas of Kyoto Prefecture have been experiencing serious depopulation with aging. The demographic phenomena have directly impacted the sustainability of rural communities. The impacts of depopulation with aging are exhaustive and on almost all aspects of rural life in the case of Gemmeinschaft-type of communities: irrigation management, co-work for agricultural road maintenance, co-work for common property such as pond and forestry, and other many functions related to daily life. Thus, the impacts of depopulation with aging are much more serious for the sustainability of community in the case of Gemmeinschaft-type of rural communities in Japan. The research used Survey Method on forty-five (45) rural communities in the areas which was done in 2011 to identify demographic factors of rural communities for their sustainability as a community. These rural communities were located in hilly and mountainous areas which generally have disadvantageous position for socioeconomic development and have small population with high percentage of elderly people who are older than 65 years old. The rural community, whose elderly people share higher than $50 \%$ of the total population, is called "a marginal village" indicating a difficulty of maintaining community activities. However, despite the similar circumstance, those communities demonstrated different dynamism of community activities.
\end{abstract}

Keywords: Japanese Rural Community, Depopulation with Aging, Sustainability of Community, Gemmeinschaft-type of Community

\section{Introduction}

Japanese population has been decreasing gradually from 128 million in 2010 associating with aging. This demographic change has not occurred evenly but created more differentiation. The urban population has increased while the rural population has decreased because of the rural-urban migration. Even within the rural sector, this demographic change has accelerated the differentiation among villages based on the locational conditions. Within ten years from 2000 to $2010,37 \%$ of all villages in nationwide increased their component households while $51 \%$ of them decreased their households. However, in the urban-fringe areas, 58\% of all villages increased their households while $36 \%$ of them decreased their households. In contrast, in the hilly and 
mountainous areas, the percentages of villages increasing their households were only $30 \%$ and $21 \%$, while the percentages of villages decreasing their households were $58 \%$ and $66 \%$, respectively.

This indicates that the impact of this demographic phenomenon of reduction has more strongly and directly impacted to the rural sector, especially the disadvantageous areas such as hilly and mountainous areas. This paper deals with identifying objective variables associated with community dynamism in those disadvantageous villages in hilly and mountainous areas and clarifying the process of this demographic reduction.

Agriculture owes its characteristics to the fact that it is an organic manner of production while other industries such as manufacturing are inorganic production. Thus, the forms of agricultural production are heavily dependent on natural conditions (weather, geographic features, water supply, etc.) which are peculiar to regions or local conditions. At the same time, the regionally peculiar characteristics of agriculture are intensified by the social environment, that is, the lifestyle of the people in the region who are economic entities. Land, labor and capital, which are the inputs needed for agricultural production, vary qualitatively and quantitatively from region to region. The regional peculiarities bring a different type of development path to regional agriculture.

Thus, Japanese agriculture (wet climate area and traditional society or densely populated society) and American agriculture (dry climate area and new society or scarcity populated society) develop in completely different, in fact, contrasting ways. The former is oriented toward labor-intensive type of agriculture with the improvement of land productivity as a distinctive feature, while the latter is geared to labor-saving type of agriculture with the improvement of labor productivity as an objective. In the case of Japanese agriculture, investment is made in current capital to accelerate technological innovation concerning the objects of labor, while in the case of America agriculture capital is invested in fixed assets to accelerate technological innovation concerning the means of labor.

Those differences in agriculture are also directly associated with the nature or characteristics of rural communities. Japanese rural communities which are largely dependent on paddy-rice farming have the strong labor-intensive type of community or group-oriented society while American rural communities which are largely dependent on up-land crop firming have the strong labor-saving type of community or individualoriented society. The former is called as the Gemmeinschaft-type of rural community while the latter is called as the Gessellschaft-type of rural community. This difference is directly associated with the linkage between individual farming and community. The Gemmeinschaft-type of rural community requires strong community commitment for resource management of production based on co-work system at the community level and thus an individual farm management is significantly dependent on the community decision making. In contrast to the Gemmeinschaft-type, the Gessellschaft-type of rural community is based on the individual farm decision making for resource management. The typical case related to this difference is observed in water supply systems: community supply system in the case of the Gemmeinschaft-type of community while agent supply system in the case of the Gessellschaft-type.

Therefore, the depopulation with aging impacts much more strongly to the Gemmeinschaft-type rural community than the Gessellschaft-type community. When a rural community reaches more than $50 \%$ in the percentage of aged people (older than 65 
years old), the community is determined as a marginal village which could face many difficulties to sustain the normal community. In 2010, the marginal villages were 13,021 nationwide which shares $9.4 \%$ of all villages and $52 \%$ of them $(6,833)$ were located at mountainous areas. This means that $25.9 \%$ of the villages in the mountainous areas are marginal villages in Japan. The national prediction of marginal villages indicates that the total number of marginal village in nationwide will increase by 1.8 times to 23,669 in 2050 which will be $17.0 \%$ of all nationwide villages and the number of marginal villages in the mountainous areas will increase to 10,395 which means $39.3 \%$ of all villages in the areas in 2050

\section{Method}

The study employed Survey Method. Kyoto Prefecture having almost the same degree of depopulation associated with aging (aging-ratio $=27 \%$ ) has also experienced the diversified development of depopulation with aging. In Kyoto Prefecture, there are 1684 villages, $70 \%$ of which are in the northern areas which are mostly mountainous areas. However, the percentage of marginal villages in the 1186 villages in the northern prefecture reached $25 \%$ in 2015 while the percentage of 498 villages in the southern prefecture was $12 \%$.

The prefectural government introduced a policy of "Village of Life (Inochi no Sato in Japanese)" to support these marginal villages and then formed a research group to identify objective indices associated with the degree of dynamism of community among these marginal villages to apply the policy. Altogether 45 villages were selected from these marginal villages in the northern part. Three cabinet officers in the prefectural department of agriculture were assigned to visit all of the target villages, to interview the village leaders directly, and to evaluate the "future prospects" of the surveyed villages according to their overall judgment, deeming them "1. Villages that can adapt to regeneration measures", "2. Villages that do not know or find it difficult to make a judgment", and, "3. Those that need support and guidance, and that cannot maintain the function of the village". Among the 45 villages, 15 villages $(33 \%)$ were evaluated

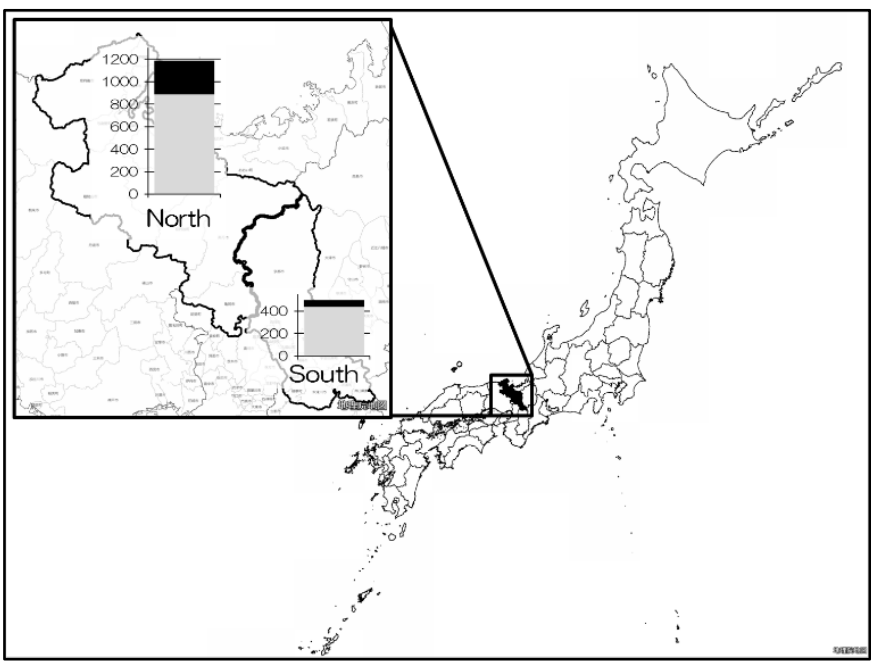

Fig. 1 Kyoto Prefecture with Village (Black bar indicatẹs marginal villages) Map source: Geographical Survey Institute (https://maps.gsi.go.jp/development/ichiran.html) as "1. Villages that can adapt to regeneration measures"; 12 villages $(27 \%)$ as " 2 . Villages that do not know or find it difficult to make a judgment"; and the rest 18 villages $(40 \%)$ as " 3 . Those that need support and guidance, and that cannot maintain the function of the village". 
Though the investigator's evaluation was a subjective judgment, it was ranked highly because they had experience of engaging with rural village communities in Kyoto. This investigator's "future prospects" evaluation index was used as the variables that would make up the most important criteria and thus this index was positioned as the most important dependent variable.

\section{Results and Discussion}

\subsection{Community Dynamism and Population}

The last census survey in 2010 has the three "categories" based on village marginality: 1. possible marginal village in the future, 2. currently marginal village, and 3. undisclosed village which had passed already the stage of marginality and is component by only few households.

Tab.1 Correlation of Demographic Variables with Future Prospects in 45 Villages in Northern Kyoto (2011)

\begin{tabular}{|c|c|c|c|c|c|}
\hline & & $\begin{array}{l}\text { Future } \\
\text { Prosperity }\end{array}$ & $\begin{array}{l}\text { Households } \\
\text { (\#) }\end{array}$ & $\begin{array}{l}\text { Ratio of Aged } \\
\text { People }\end{array}$ & $\begin{array}{l}\text { Population in } \\
\text { Farm } \\
\text { Households }\end{array}$ \\
\hline \multirow[t]{3}{*}{ Future Prospects" } & Pearson Correlation ( $r$ ) & 1 & -497 & .540 & -.186 \\
\hline & Significance Level (p) & & .001 & .000 & .220 \\
\hline & $\mathrm{N}$ & 45 & 45 & 41 & 45 \\
\hline \multirow[t]{3}{*}{ Households(\#) } & Pearson Correlation $(r)$ & -.497 & 1 & -.399 & .383 \\
\hline & Significance Level (p) & .001 & & .010 & .009 \\
\hline & $\mathrm{N}$ & 45 & 45 & 41 & 45 \\
\hline \multirow[t]{3}{*}{ Ratio of Aged People } & Pearson Correlation ( $r$ ) & .540 & -.399 & 1 & -.400 \\
\hline & Significance Level (p) & .000 & .010 & & .010 \\
\hline & $\mathrm{N}$ & 41 & 41 & 41 & 41 \\
\hline \multirow{3}{*}{$\begin{array}{l}\text { Population of Farm } \\
\text { Households }\end{array}$} & Pearson Correlation ( $r$ ) & -.186 & .383 & -400 & 1 \\
\hline & Significance Level (p) & .220 & .009 & .010 & \\
\hline & $\mathrm{N}$ & 45 & 45 & 41 & 45 \\
\hline
\end{tabular}

The correlation between the "categories" and "future prospects" is relatively strong (correlation coefficient $=.450$ ) showing the good reliability of these evaluations. In addition, the "future prospects" variable also shows a relatively strong correlation (correlation coefficient $=.497$ ) with the "number of households" indicating that the less the number of households in a village, the more severe the village's "future prospects." The "future prospects" variable also shows a relatively strong correlation with the "rate of ageing" (correlation coefficients $=.540$ ) indicating that the more population ages, the more severe the village's "future prospects" become.

Therefore, "number of households" and "rate of ageing, which are specific, objective indicators that correlated strongly with "future prospects", were used as a narrowing down index. The scatter diagram of "future prospects" and "number of 
households" shows that almost all of the villages with " 3 . that need support and guidance and cannot maintain the function of the village" are small-scale villages of less than 20 households. Moreover, the scatter diagram with the "rate of ageing" shows that of all of the "1. villages that could adapt to regeneration measures", none have more than a $70 \%$ of ageing rate.

In addition, the scatter diagram shows that almost all of the villages with the ageing rate of $40 \%$ and below are classified as " 1 . villages that can adapt to regeneration measures", and that the villages with an ageing rate of $40 \% \sim 70 \%$ are scattered in the "future prospects". Therefore, as is made clear in the three-dimensional scatter diagram between "number of households" and "rate of ageing" with the dependent variable of the "future prospects" ("1. villages that can adapt to regeneration measures"; "2. villages that do not know or find it difficult to make a judgment", and " 3 . those that need support and guidance, and that cannot maintain the function of the village"), 20 households or less as the criteria in the number of households in a village and an ageing rate of over $70 \%$ as the criteria in the aging ratio are appropriate criteria for narrowing down the villages to be targeted by the policy.

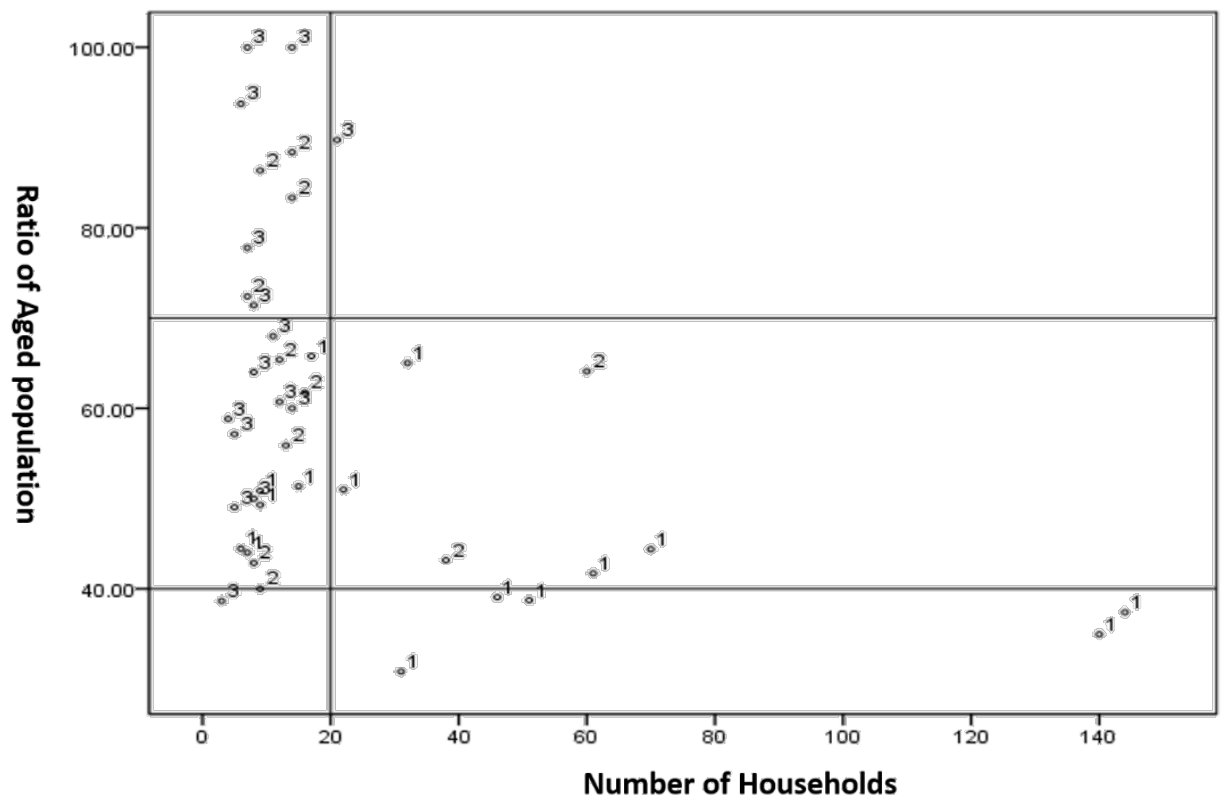

Fig.2 Scatter-gram of Rural Communities in Kyoto Prefecture $(n=45,2011)$

The second stage of narrowing down the villages to be targeted by the policy is to identify objective index variables that clarify the differences between " 3 . those that need support and guidance and cannot maintain the function of the village" and the other "future prospects" villages, whilst there are 25 villages with an ageing rate of $40 \% \sim 70 \%$ that all have scattered in "future prospects." With regard to the 25 villages with the ageing rate of $40 \% \sim 70 \%$, a variable that makes clear the difference between the "future prospects" group of " 3 . those that need support and guidance and cannot maintain the function of the village" ( 8 villages) and the other groups (17 villages) was determined by a variables t-test. From the results, it was found that there is a statistically significant difference in 10 variables, and from among them, the "total number of household 
members in farming households" variable was selected as the narrowing down criteria, which is objective to interpret because of its specific content

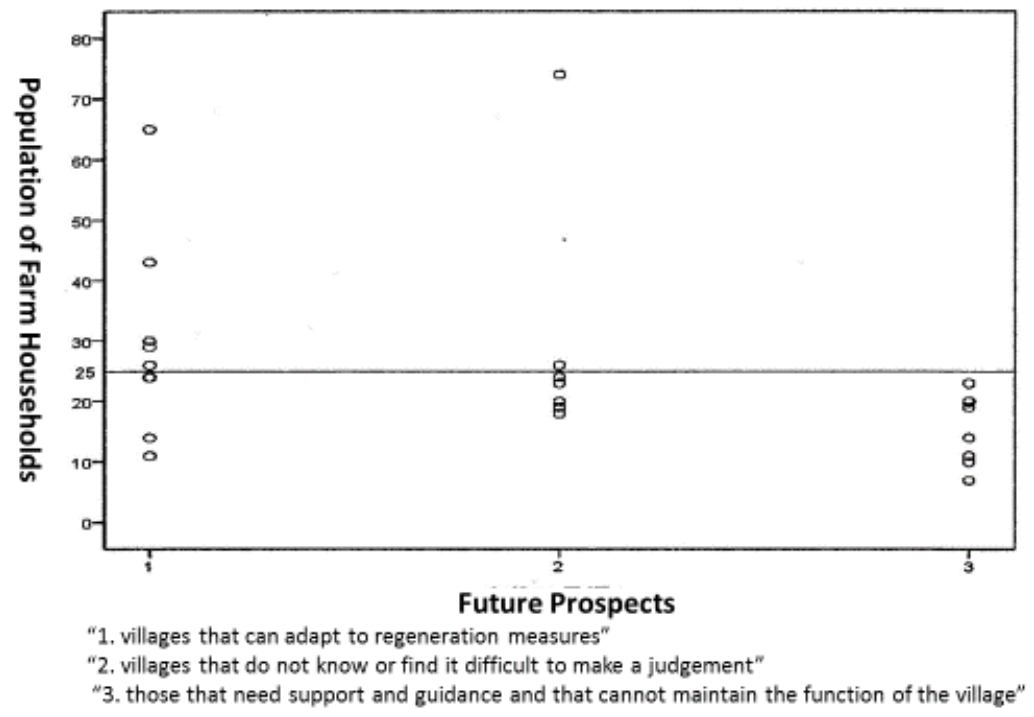

Fig.3 Scatter-gram of 25 Villages with the Aging Ratio of 40 - 70\% in Future Prospects (Northern Kyoto、2011)

There was a relatively strong correlation between the "future prospects" and "total number of household members in farming households" in the 25 villages with an ageing rate of $40 \% \sim 70 \%$ (correlation coefficient $=.380$, a statistical significance level $=6.1 \%$ ). and the trend that the less the "total number of household members in farming households" in the village, the more severe the "future prospects." All villages with "3. those that need support and guidance and cannot maintain the function of the village" had 25 and below in "total number of household members in farming households." Therefore, in the second stage of narrowing down the villages to be targeted by the policy, the village group that had an ageing rate of $40 \% \sim 70 \%$ having 25 or less in "total number of household members in farming households" was taken to be the narrowing down criteria for villages to be targeted by the policy

\subsection{Future Prospects for Household Farming}

The research purpose was to clarify objective variables and criteria to identify the marginal villages for applying the prefectural government policy of "Village of Life (Inochi no Sato in Japanese)" to support those marginal villages. The research found the clear relationship between the dynamism of community and the demographic characteristics which are objective variables. The objective variables/indices and criteria are necessary conditions for policy application since the objectivity of judgment is always required for the government in order to keep the fairness to people.

The research output clarified three variables for criteria to identify marginal villages to apply the policy. The first variable was the number of households in a village and the criterion was 20 households or less. There was no village having "future prospects" of 
the " 3 . that need support and guidance and cannot maintain the function of the village" among the villages having more than 20 households. The second variable was the ratio of aged people in village population (rate of aging) and the criteria were $40 \%$ and below and over $70 \%$. All of the village having $40 \%$ and below in the rate of aging were classified as " 1 . villages that can adapt to regeneration measures" in the community dynamism of "future prospects" but all of the village having over $70 \%$ in the rate of aging were classified as " 3 . that need support and guidance and cannot maintain the function of the village" in the community dynamism evaluation. The third variable was the total number of household members in village households and the criterion was 25 or less. All of the village having over 25 in the number of members in village households, or village population, was classified as "3. that need support and guidance and cannot maintain the function of the village" in the community dynamism evaluation

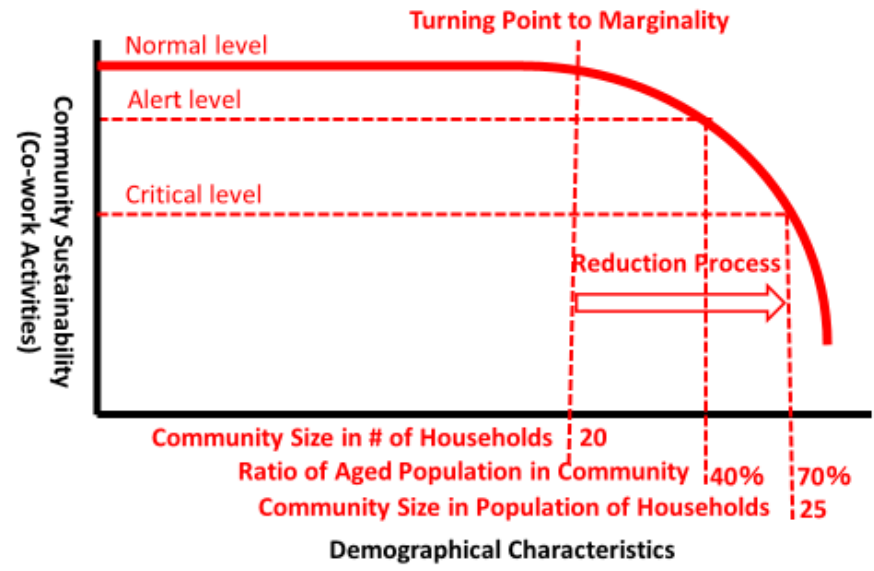

Fig.4 Marginality of Gemeinschaft- type of Rural Communities in Depopulated Aging Society in Japan

Those results indicate the Japanese general framework of development path of villages or marginality of community dynamism from normal level, at which the community has enough capability to carry out the community co-work activities especially for management of farming resources such as water supply system, to critical level at which the community has very week capability to maintain the community cowork activities and thus faces to the risk of extinguishment. The turning point of the community dynamism from the normal level to reduction process is the community size of 20 households or less. This reduction of households is associated with population aging and then, when the rate of aged population hits $40 \%$, some of the communities start having a difficulty to maintain the community dynamism at normal level. The critical level is when the community reaches the $70 \%$ and over in the rate of aged people and shrinks to 25 people in the community population size. The government is required to introduce any necessary policy to adapt this reduction process of community dynamism before the critical level. 


\section{Conclusion}

Rural communities were located in hilly and mountainous areas, which generally have disadvantageous position for socioeconomic development and have small population with high percentage of elderly people who are older than 65 years old. The rural community, whose elderly people share higher than $50 \%$ of the total population, is called "a marginal village" indicating a difficulty of maintaining community activities. However, despite the similar circumstance, those communities demonstrated different dynamism of community activities.

\section{References}

Government of Japan (2017) White Paper of aging Society (Overview), Cabinet Office (in Japanese).

Government of Japan (2011) White Paper of Food, Agriculture and Rural Areas, Ministry of Agriculture, Forestry and Fishery (MAFF) (in Japanese).

Hashizume, Noboru (2015) Trend and Forecast of Agricultural Villages: Dynamic Analysis of Community Structure and Marginal Villages, Primaff Review No.63, pp.4-5 (in Japanese).

Kawamura, Yoshio (2017) "Alternative Development from Frodism to Nichism for Asian Agriculture in Globalizing Era," Journal of Asian Rural Studies, 1(1), January, pp.1-12.

Kyoto Prefectural Government (2016) Rural Action Plan, Department of Agriculture, Forestry and Fishery (in Japanese).

Ohno, Akira (2008) Marginal Village and Rural Regeneration, Kyoto Newspaper Publication Center, pp.313 (in Japanese)

Odagiri, Tokumi (2012) Rural Regeneration in Japan, Centre for Rural Economy Research Report, Center for Rural Economy, University of New Castle upon Tyne, pp.41 (ISBN 1903964377242 22). 